www.jmscr.igmpublication.org

Impact Factor (SJIF): 6.379

Index Copernicus Value: 71.58

ISSN (e)-2347-176x ISSN (p) 2455-0450

crossref DOI: _https://dx.doi.org/10.18535/jmscr/v6i2.180

Journal Of Medical Science And Clinical Research

\title{
Ewing's Sarcoma of Nasal Cavity- A Case Report
}

\author{
Authors \\ Dr K.Srinivas Rao ${ }^{1}$, Dr Lalitha Reddy.K ${ }^{1}$, Dr Sanjay.R ${ }^{1}$, Dr.Varun.S , Dr Milap Shah ${ }^{2}$ \\ ${ }^{1 * D e p a r t m e n t}$ of Radiation Oncology, ${ }^{2}$ Department of Pathology \\ Yashoda Hospital, Secunderabad, Telangana, India \\ Corresponding Author \\ Dr Lalitha Reddy.K.
}

Address: Flat no 410, Narmada Sarovar, Indra nagar, Near GPRA quarters, Gachibowli, Hyderabad, 500032

Telangana, India

Ph no: 9908928492, Email: lalitha.kudumula@gmail.com

\begin{abstract}
Ewings sarcoma/Primitive Neuroectodermal tumors are a group of tumors characterised by small round cells seen in children and adolescence that rarely affect the bone and soft tissues of the nasal cavities. Incidence of tumors in head and neck is $2-7 \%^{[1,2]}$, with mandible and maxilla being the most common sites and sinonasal tract is very rare to involve ${ }^{[1-3]}$. Here we report a case of Ewing's sarcoma of nasal cavity in an 13 years old adolescent male who was diagnosed on histopathology at his local place as Esthesioneuroblastoma.
\end{abstract}

Keywords: Ewing's sarcoma, Esthesioneuroblastoma, Peripheral neuroectodermal tumor, Sinonasal tract.

\section{Introduction}

Ewings sarcoma is a highly malignant, small round cell tumor that originated from the primitive neuroectodermal cells, as first described by James Ewing in $1921^{[4]}$. Ewings sarcoma has two variants: Skeletal and Extra skeletal but it sometimes difficult to seperate the two entities. Ewings sarcoma is usually found in long bones of extremities in children and young white adults, with a peak incidence in second decade with constant male predominance ${ }^{[2]}$. It is the second most common pediatric bone tumor. Head and Neck area is rarely involved either by skeletal and extra skeletal subtype, with the mandible and the skull being the preferential sites of origin ${ }^{[5]}$. Sinonasal tract involvement is extremely rare, with only 14 cases of EWS reported in the worlds's otolaryngology literature ${ }^{[1,7,12]}$. We report one such case of Ewings sarcoma of nasal cavity in an adolescent boy which was diagnosed as Esthesioneuroblastoma on histopathology.

\section{Case report}

A 13 years old adolescent boy presented with chief complaints of nasal blockade since 2 months, headache in the frontal and parietal region which is throbbing in nature, swelling of nasal bridge associated with both eyes pain, snoring at night, loss of weight and decreased appetite. He has not given any history of trauma, epistaxsis. On physical examination, bulge over root of nasal septum is evident with tenderness, with widenned medial 
canthi. Fig 1. His bilateral vision was 6/6. Had an ENT consulatation at his local place and on Rhinoscopy, bilateral septal soft bulge was noted. His CT Paranasal sinuses scan was showing large soft tissue opacity in nasal and ethmoidal region with nasal septum destruction and bilateral medial maxillary antrum walls, ethmoidal cribriform bony plate dehiscence with intracranial mild extension assocciated with left side orbit-ethmoidal wall destruction. S/o Infective osteomyelitis mass or ethmoidal sinus polyposis mass. MRI PNS scan was showing $5.4 * 3.6 \mathrm{~cm}$ large heterogenously enhancing altered signal intensity lesion in nasal cavity with its expansion and with involvement of both ethmoid sinuses and destruction of cribriform plate with mild intracranial extension, isointense on T1W and heterogenous hyperintense on $\mathrm{T} 2 \mathrm{~W}$ image. S/o Esthesioneuroblastoma or Olfactory neuroblastoma. Mucosal thickenning in $\mathrm{B} / \mathrm{L}$ maxillary, ethmoid and sphenoid sinuses. s/o sinusitis. Fig 2. His laboratory tests were normal. He underwent biopsy outside from the midline mass over nassal septum and ethmoids. Histopathology was suggestive of Malignant small round cell tumor,s/o Olfactory neuroblastoma. Upon IHC in our hospital the tumor cells were positive for CD99 and FLI-1, negative for Chromogranin, synaptophysin, desmin, myogenin and focal dot positive for $\mathrm{CK}$, suggesting diagnosis in favour of Ewings sarcoma. Fig 3.

Patient was further evaluated with Whole body PET CT scan which was s/o FDG avid large heterogenously enhancing lesion in the nasal cavity extending into nasopharynx, bilateral ethmoidal sinuses and base of skull causing expansion of nasal cavity with thinning of medial wall of bilateral maxillary sinuses and cribriform plate (SUV max:7.5)- Primary with no evidence of metastatic disease. Fig 4.

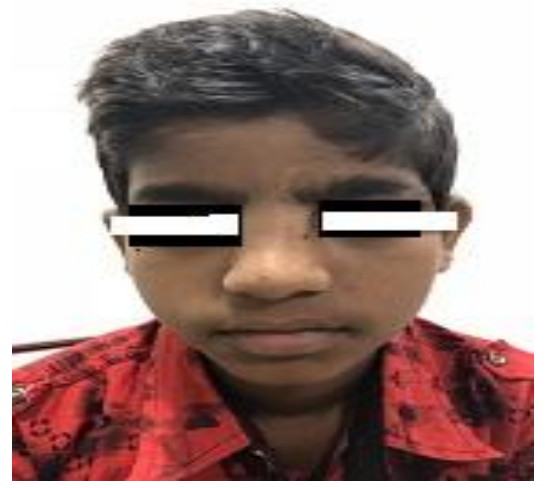

Fig 1: Patient has broadenned nasal bridge

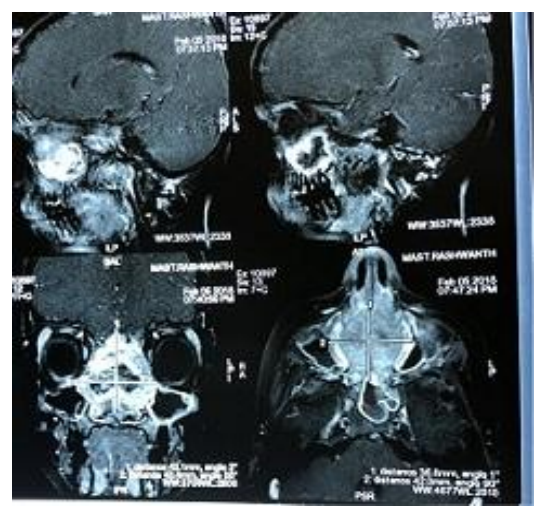

Fig 2 MRI PNS showing heterogenous Hyperintense lesion on T1W image.

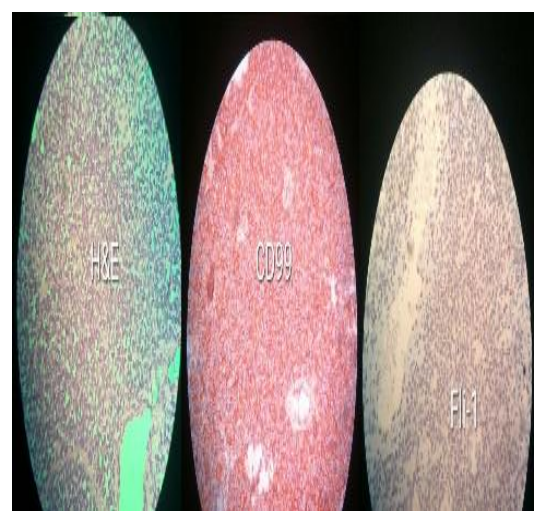

Fig 3: HPE showing malignant round cell tumor, Positive for CD99 and FLI-1.

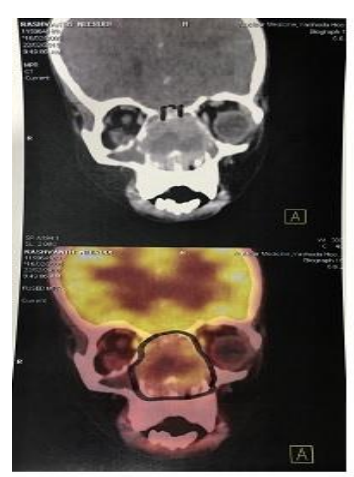

Fig 4: PET CT showing ethmoidonasal Mass with intracranial extension. 


\section{Discussion}

Ewing's Sarcoma is a highly malignant, small, round cell tumor that originates from the primitive neuroectodermal cells. It was first described by James Ewing in $1921^{[4]}$. Ewings sarcoma(EWS) and PNET are closely related family of small round cell sarcomas with varying degrees of neuroectodermal differentiation ${ }^{[1-3]}$. PNET show neuroectodermal differentiation, whereas Ewings sarcoma lack them as assessed by light microscopy, immunohistochemistry and electron microscopy ${ }^{[2]}$. Primary EWS commonly occurs in early childhood or adolescence and rarely occurs in adulthood. There is a slightly male predominance with a male to female ratio of $1.5: 1^{[1,2,6]}$. The skelatal variant is more frequent and occurs in long bones of the extremities. The extraskeletal form has the same histological, immunohistochemical and molecular features of skelatal variant and affects soft tissue of lower limbs, paravertebral tissues, chest wall, retroperitoneum. Primary EWS of the head and neck region is extremely rare and accounts for only $4-9 \%$ of all EWS's ${ }^{[5,8,9,10]}$. Mandible and maxilla are the mst common sites affected in the head and neck region and involvement of para nasal sinuses is very rare. In general, approximately $20-30 \%$ of EWS patients present with metastases at the time of their diagnosis. Patients with EWS of the head and neck region less frequently have metastasis at diagnosis.

The pathogenesis of the tumor is still unclear; however a specific chromosomal translocation (t11:22) (q22:q12), which is present in upto 90\% of cases and has an important role. Imaging studies like Computerised tomography and MRI are essential for the diagnosis, however EWS images are not specific. In our case CT PNS was suggestive of infective osteomyelitis or ethmoidal polyposis mass. MRI PNS was more pointing towards Esthesioneuroblastoma or Olfactory neuroblastoma.

Histologically these tumors are composed of uniform small round cells with round nuclei containing fine chromatin and scant clear or eosinophilic cytoplasm. In the sinonasal tract, the differential diagnosis includes all tumors that are composed of small round cells like olfactory neuroblastoma, undifferentiated carcinoma, lymphoma, sinonasal melanoma, acute leukemia, embryonal rhabdomyosarcoma, sinus mesenchymal chondrosarcoma, osteosarcoma small cell and small neuroendocrine cell carcinoma.

The definitive diagnosis requires a Histopathological examination, immunohistochemistry and a cytogenetic analysis. The essential diagnostic test to differentiate EWS from many small round cell neoplasms is the CD99 marker, which is detected on IHC. In addition molecular studies using PCR to detect the characteristic chromosomal translocation are definitive for Ewing's sarcoma. The gene sequence, $t(11 ; 22)(q 24 ; q 12)$, which results in the fusion of the EWS gene with the FLI gene, is a specific genetic hallmark of EWS ${ }^{[11-13]}$. In our case, the patient was positive for CD99, FLI-1 gene favoring Ewings sarcoma as the diagnosis and negavtive for chromogranin, synaptophysin, desmin, myogenin ruling out the chances of small cell carcinoma, poorly differentiated sinonasal carcinoma, olfactory neuroblastoma or lymphoma.

The treatment options include surgery, Chemotherapy and or Radiotherapy ${ }^{[14]}$. The most effective treatment is Surgery followed by Chemotherapy or Radiotherapy. In inoperable cases due to unresectability of the tumor due to its extension or patient's medical co-morbidities, the chemotherapy and radiotherapy is valid option. Combination chemotherapy with Vincristine, doxorubicin, cyclophosphamide and actinomycin is more effective than monotherapy ${ }^{[14,15]}$. Radiation is reserved for patients with inoperable tumors. Local control is seen in $85 \%$ of the cases with $5 \mathrm{yr}$ survival rate of $55-60 \%^{[1]}$. In our case, Patient had unresectable tumor because of cribriform plate extension and intracranial extension. His Whole body PETCT was suggestive of primary lesionwith locoregional extension without distant metastasis. 


\section{References}

1. Yeshvanth SK, et al. Rare case of extraskeletal Ewings sarcoma of the sinonasal tract. J Cancer Res Ther. 2012;8;142-4.

2. Howarth KL, Khodaei I, Karkanevatos A, Clarke RW. A sinonasal primary Ewing's sarcoma. Int J Pediatr Otorhinolaryngol. 2004;68;221-4.

3. Aferzon M, Wood WE, Powel JR, Ewing's sarcoma of the ethmoid sinus. Otolaryngol Head Neck Surg. 2003;128:897-901.

4. Ewing J: Diffuse endothelioma of bone. Pathol Soc 1921;21:17-24.

5. Siegal GP, Oliver WR, Reinus WR, Gilula LA, Foulkes MA, Kissane JM, Askin FB: Primary Ewing's sarcoma involving the bones of head and neck. Cancer 1987;60:2829-2840.

6. Csokonai LV, Liktor B, Arató G, Helffrich F: Ewing's sarcoma in the nasal cavity. Otolaryngol Head Neck Surg 2001;125:665-667.

7. Coskun BU, Cinar U, Savk H, Basak T, Dada B: Isolated maxillary sinus Ewing's sarcoma. Rhinology 2005;43:225-228.

8. Allam A, El-Husseinty G, Khafaga Y, Kandil A, Gray A, Ezzat A, Schultz H: Ewing's sarcoma of the head and neck: a retrospective analysis of 24 cases. Sarcoma 1999;3:11-15.

9. Carlotti CG Jr, Drake JM, Hladky JP, Teshima I, Becker LE, Rutka JT. Primary Ewing's sarcoma of the skull in children. Utility of moleculer diagnostics, surgery and adjuvant therapies. Pediatr Neurosurg 1999;31:307-315.

10. Desai KI, Nadkarni TD, Goel A, Muzumdar DP, Naresh KN, Nair CN: Primary Ewing's sarcoma of the cranium. Neurosurgery 2000;46:62-68.

11. Kawabata M, Yoshifuku K, Sagara Y, Kurono Y: Ewing's sarcoma/primitive neuroectodermal tumour occurring in the maxillary sinus. Rhinology 2008;46:75-78.
12. Gupta S, Gupta OP, Mehrotra S, Mehrotra D: Ewing sarcoma of the maxilla: a rare presentation. Quintessence Int 2009;40:135-140.

13. Iezzoni JC, Mills SE: "Undifferentiated" small round cell tumors of the sinonasal tract: differential diagnosis update. Am $\mathbf{J}$ Clin Pathol 2005;124(suppl):S110-S121.

14. Velche-Haag B, Dehesdin D, Proust F, Marie JP, Andrieu-Guitrancourt J, Laquerriere A. Sarcome d'Ewing et localisations ORL: A propos d'un cas. Ann Olaryngol Chir Cervicofac.2002;119:363-8.

15. Boor A, Jurkov I, Friedmann I, Plank L, Kocan P. Extraskeletal Ewing's sarcoma of the nose. J Laryngol Otol. 2001;115:74-6. 